\title{
The Spatial Meaning of Sıó with the Accusative in Homeric Greek
}

\author{
Silvia Luraghi \\ Università di Pavia, Dipartimento di Linguistica Teorica e Applicata, \\ Strada Nuova 65, 27100 Pavia, Italy \\ silvia.luraghi@unipv.it
}

Received: May 2010; accepted: August 2010

\begin{abstract}
The semantic difference between spatial usages of $\delta$ id with the accusative and with the genitive in Homeric Greek is not clearly described in reference works. The available literature leaves readers the feeling that there is wide overlap between the two cases, possibly to be explained through metrical factors. This paper is an attempt to shed light on the issue, through a careful scrutiny of all passages in which the preposition occurs. It turns out that, if the analysis is extended to a large enough context, semantic motivations for the occurrence of either case can be detected, which lead to a distinction between the genitive on the one hand, and the non-directional and directional accusative on the other. While the genitive occurs in passages in which a unidirectional path or a simple location are indicated, the non-directional accusative indicates multidirectional path or multiple location. Finally, the directional accusative indicates that an entity is crossed over. The semantic description makes use of concepts and terminology common in cognitive grammar.
\end{abstract}

\section{Keywords}

meaning of prepositions, Homeric Greek, case variation, unidirectional vs. multidirectional path, directional vs. non-directional accusative 


\section{Introduction ${ }^{1)}$}

This paper is devoted to the spatial meaning of the Ancient Greek preposition $\delta i \alpha$ with the accusative in Homeric Greek. As is well known, spatial use of this preposition is limited to Homer: later, $\delta i \alpha$ only preserved its abstract meaning when occurring with the accusative, and indicated cause, while spatial meaning remained limited to $\delta \dot{\alpha}$ with the genitive. In addition, occurrences where $\delta$ i $\alpha$ with the accusative has a concrete spatial meaning are not numerous in Homer, and they are partly formulaic (see the data below). Thus, spatial expressions with $\delta\llcorner\dot{\alpha}$ and the accusative have puzzled grammarians and philologists since antiquity, and scholiasts have often suggested various textual emendations in order to make the language closer to their norm. Doubts mostly concerned the semantic difference between $\delta\llcorner\dot{\alpha}$ with the accusative and $\delta\llcorner\dot{\alpha}$ with the genitive: such doubts can still be found in modern accounts of the usage of this preposition. It is the aim of the present paper to shed some light on this issue.

The paper is organized as follows. In the first section, I review some relevant principles of cognitive grammar, the theoretical framework that I am going to adopt in the rest of the discussion. In the second section, I briefly describe the usage of $\delta\llcorner\alpha$ in Homeric Greek. In section 3, I summarize the findings in Luraghi 2003 concerning case variation within prepositional phrases (PPs) in Homeric Greek. I then pass on to the usage of $\delta$ i $\alpha$ with the genitive and with the non-directional and directional accusative (section 4 ). In section 5 , I discuss case variation in connection with types of landmark. Section 6 contains a recapitulation.

\section{Theoretical Framework}

In my account of the use of $\delta i \alpha$, I will use the theoretical framework and the terminology of cognitive grammar, in which grammatical forms, such as prepositions and cases, are assumed to be meaningful elements. Following this approach, there is no distinction between grammar and the lexicon: the difference between the meaning of a lexeme and the meaning of a grammatical form, such as a case, is only a matter of degrees of abstractness. This means that in an Ancient Greek prepositional phrase

1) I would like to thank Mnemosyne's anonymous referee for helpful comments on an earlier version of this paper. 
one has to account for the meaning of the preposition and for the meaning of the case; consequently, case variation is regarded as meaningful.

Relations such as those indicated by prepositions are represented as holding between a foregrounded entity, the trajector, and a backgrounded one, the landmark. ${ }^{2)}$ Thus, in a sentence such as (1):

\section{(1) Mary is going to school}

the NP Mary indicates the trajector and the NP school indicates the landmark. As in (1), it may be the case that the relation between a trajector and a landmark implies the existence of a trajectory, along which the former moves with respect to the latter. ${ }^{3)}$ This is most often the case in PPs with $\delta$ ' $\alpha$ with the accusative, which mostly occur with motion verbs or verbs of other types which also imply the existence of a trajectory, as we will see below.

Trajectors, landmarks and trajectories may display a wide range of differences regarding their structure. In the case of trajectors and landmarks, this fact is reflected by the nature of possible NPs: trajectors and landmarks may be expressed by singular count nouns, plural count nouns (sometimes limited to a certain number of referents, typically two), or mass nouns. Some prepositions may occur with any type of trajectors and landmarks, but some are constrained in their use. For example, English among cannot normally occur with singular count nouns, but requires a plural number. In addition, when the quantity of referents referred to by a plural count noun is limited to two, another preposition, between, is normally used instead of among. The features reflected by grammatical number refer to a property of referents called 'plexity', following the terminology in Talmy 1988: plural and mass nouns refer to multiplex entities, singular count nouns to uniplex, and plural count nouns limited to two to biplex entities (see Luraghi 2003, 245 for this last term). ${ }^{4)}$ The distinction

2) On the trajector/landmark alignment see Langacker 1987, 231-6.

3) See Taylor 1991. Note that, although the name 'trajector' might be taken to imply movement, this is not the case, and the trajector/landmark alignment also applies to stationary situations (this can also be the case with $\delta\llcorner\alpha$, though less frequently, see section 4.1.3).

4) Uniplex entities may occur with prepositions that require biplex trajectors. Biplex entities can also be indicated by singular count nouns when the two-sided nature of the entity is emphasized, as is the case with landmarks occurring with $\alpha \mu \varphi i$, cf. Luraghi $2003,256$. 
between plural count and mass nouns reflects a distinction in (the way of conceiving) a referent's internal structure: while plural count nouns indicate that a referent is constituted by a plurality of single entities, mass nouns indicate that the internal structure of a certain referent is not further analyzable or divisible. Accordingly, the former are called multiplex discontinuous and the latter are called multiplex continuous.

In the case of motion events, possible differences also concern the structure of the trajectory along which the trajector moves: a trajectory may be unidirectional and thus clearly traceable, or it may take different directions and escape clear traceability, as shown in (2) and (3):

(2) The river flows through the plain.

(3) The frightened boy ran around the room screaming.

While a river's course, windy as it may be, can normally be traced, and the water flows eventually toward a certain goal (typically, another river or the sea), the situation described in (3) indicates that a certain trajector (the boy) changes direction and does not move toward any specific goal. Note that the same preposition may indicate unidirectional or multidirectional path, depending on the type of landmark, as shown by comparison of (3) and (4):

(4) The frightened boy ran around the corner.

When the trajectory is partly or totally contained by the landmark, the internal structure of the landmark may also be reflected in the structure of the path. Since this is precisely what happens in the case of $\delta \dot{\alpha} \alpha$, I leave the discussion for the next sections.

Prepositional phrases express (or indicate) semantic roles. For example, the PP to school in (1) indicates direction. In Ancient Greek, case variation with the same preposition may also indicate variation in semantic roles. For example, in Classical Greek $\delta$ i $\alpha$ with the accusative always expresses cause, while $\delta i \alpha$ with the genitive may express path, intermediary or instrument (see Luraghi 2003, 177-84). Thus, case variation has the function of distinguishing cause from other possible semantic roles expressed by the same preposition. However, different cases with the same preposition 
do not always indicate different semantic roles. Often, the semantic role is the same, and the difference must be found somewhere else.

When the semantic role expressed remains the same, case variation with the same preposition can best be captured in terms of profiling: different aspects of the relation between the trajector and the landmark are highlighted. Similar considerations hold for variation of prepositions in a language such has English, which has no cases. Consider examples (5) and (6):

(5) I went to the station and took the 5 p.m. train.

(6) I went into the station (and took the 5 p.m. train).

The PPs to the station and into the station express the same semantic role, direction. In both cases, the normal interpretation is that the trajector not only reaches the landmark, but also its interior (this is shown by the acceptability of (5): based on common knowledge, one has to enter a station in order to take a train, rather than remain in the vicinity of the station). ${ }^{5)}$ However, the choice of to vs into responds to the intention of the speaker to focus on different parts of the trajectory: in particular, the use of into in (6) indicates a special focus on the end segment of the trajectory, which leads the trajector inside the landmark. We can then say that while to in (5) profiles the trajectory, into in (6) profiles its end segment.

\section{Cases with Prepositions in Homeric Greek}

As is well known, Homeric Greek displayed a wider range of case variation than later classical prose. In addition, often case variation is not associated with different semantic roles in Homer: I have mentioned above the

\footnotetext{
5) Indeed, the fact that example (6) sounds more normal without the addition of the second clause reflects profiling properties of into: one is likely to use into when one needs to specify that the trajector does not remain outside the landmark. Since this is the common inference also when one uses to, when describing the normal situation in which someone goes to the station to take a train one usually does not add unnecessary information regarding the end segment of the trajectory.
} 
case of $\delta$ เ $\alpha$, which is the topic of this paper; another clear case is $\mu \varepsilon \tau \dot{\alpha}$, which could have the meaning 'among' in location expressions with three cases in Homer. Later, it only expressed the semantic role of comitative with the genitive, while its meaning with the accusative was 'after', 'across', 'beyond'. Similarly, $\pi \varepsilon p$ i could express location with three cases in Homeric Greek. In Attic-Ionic prose, $\pi \varepsilon p i$ with the genitive lost its spatial usage, and indicated topic or cause of emotion, while the accusative retained a wider range of concrete and abstract meanings. Occurrence with the dative was increasingly limited and eventually completely disappeared: by the time of the koine $\hat{e}$, the preposition could only take two cases. Spatial usage of $\pi \varepsilon p i$ with the dative is virtually limited to certain types of landmarks (typically body parts) in classical authors already.

The situation described above is due to the increasing grammaticalization of prepositions, which also displayed a wider range of behaviors on the syntactic plane in Homeric than in Classical Greek: as is well known, the Indo-European preverbs-adpositions originally were free standing adverbs, and as such they still occur in the Homeric poems. As Chantraine $(1953,82)$ points out in an often quoted passage, it is often difficult (or better, pointless $)^{6)}$ to indicate whether they function as adpositions, preverbs, or adverbs. As a consequence, the meaning of a specific preposition co-occurring with an NP inflected in a specific case was conventionalized to a limited extent only, as one can see especially in occurrences where prepositions have spatial meaning. In addition, spatial usage of cases without prepositions was more extended in Homer than in later prose: therefore, case variation was used extensively for further differentiation of the same semantic role, without each case being limited to one specific semantic role.

In Homeric Greek, two patterns typically emerge from the analysis of case variation with the same preposition, one of which is connected with variation in semantic roles, while the second is not. In the first pattern, the three cases may indicate three different spatial relations: location (dative), direction (accusative), and source (genitive). An example where case variation most often indicates different semantic roles in Homeric Greek is constituted by $\pi \alpha \rho \alpha$ : with this preposition, the dative indicates location, the genitive indicates source, and the accusative mostly indicates direction. The function of case variation with $\pi \alpha \rho \alpha$ is also consistent with the function

6) See the recent discussion in Haug 2009. 
of cases with a number of prepositions which do not allow for case variation, such as ह่ (which takes the dative and indicates location), हiऽ (which takes the accusative and indicates direction), $\dot{\varepsilon} x$ and $\dot{\alpha} \pi \dot{o}$ (which take the genitive and indicate source). ${ }^{7)}$ The connection of cases with specific semantic roles described above goes back to the local meaning of cases in PIE, as reflected in Greek after case syncretism: as is well known, the locative merged with the dative and the genitive merged with the ablative.

The second pattern of case variation with prepositions in Homeric Greek is less known or described; it involves the genitive and the accusative, and the semantic roles involved are most often location or, as with $\delta i \alpha$, path. Note that the two cases do not have the meaning that they usually have in the first pattern of variation: in other words, in this second pattern of variation, the genitive does not convey the meaning of an ablative, and the accusative is not directional. Rather, the distinction between the accusative and the genitive reflects the partitive meaning of the latter, and results in the opposition total/partitive, which is based on plexity. ${ }^{8)}$ Let us consider location expressions. A number of prepositions exhibit a typical pattern, by which the genitive occurs with plural count nouns, i.e. multiplex discontinuous landmarks, and the accusative with mass nouns, i.e. multiplex continuous landmarks. This can best be seen with $\mu \varepsilon \tau \dot{\alpha}$, in occurrences where the resulting PPs express location (that is, not with motion verbs). ${ }^{9)}$ The accusative occurs with mass nouns, such as $\pi \lambda \eta \theta \dot{s}$, "̋ $\mu \lambda \circ \varsigma_{\varsigma}$ 'crowd', or count plurals with the adjective $\pi \hat{\alpha} \varsigma$ 'all', while the genitive occurs with plural human (i.e. highly individuated) count nouns or personal pronouns. This distinction was newly introduced in the case of $\mu \varepsilon \tau \dot{\alpha}$, as shown by the fact that the genitive only occurs in a limited number of passages. The dative, which was most likely older, but which was later abandoned, could occur with all types of landmark; it was also the

\footnotetext{
7) As is well known, spatial meaning of Greek cases is connected with case syncretism; the three prepositions $\dot{\varepsilon} v$, $\varepsilon \dot{\xi}$ and $\dot{\varepsilon} \varkappa$ were already much more common than plain cases in Homeric Greek, and can be seen as substitutes for cases in the encoding of the three basic spatial relations locative, allative and ablative, see Luraghi 2009 .

8) See Luraghi 1988 and 2003. The fact that the plain accusative could not only indicate direction and function as an allative in Ancient Greek is described in reference grammars, which mention the so-called 'accusative of extension' indicating extension in space or duration in time, see Schwyzer 1950, 67-70, Chantraine 1953, 45-6.

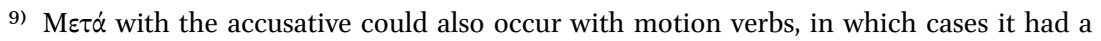
directional meaning, see Luraghi 2005 .
} 
only case that could occur with a plural referring to two referents and mean 'between', as in $\mu \varepsilon \tau \dot{\alpha} \chi \varepsilon \rho \sigma i$ 'between (one's) hands' (e.g. Od. 3.281).

Note that both the genitive and the accusative could occur without prepositions in non-directional space expressions, though to a more limited extent that the dative. In such cases, the genitive indicates a location, while the accusative has a perlative meaning; it mostly occurs with nondirectional usages of motion verbs. In some occurrences, the two cases seem to convey quite similar meanings. Examples are:

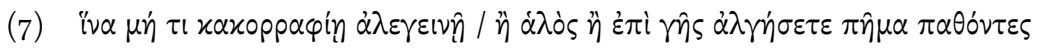
(Od. 12.26-7)

In order that ye may not suffer pain and woes through wretched illcontriving either on sea or on land

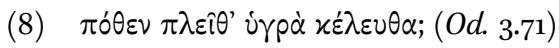

Whence do ye sail over the watery ways?

Variation between the accusative and the genitive in (7) and (8) relies on the opposition total/partitive, illustrated above. Occurrences of this type where the genitive and the accusative occur without prepositions are few, while occurrences with prepositions are much more numerous. The opposition total/partitive between the accusative and the genitive lost its relevance after Homer; as a result, the tendency for case variation with the same preposition to be associated with different semantic roles, observed above for $\delta \iota^{\alpha}$ and $\mu \varepsilon \tau \alpha \dot{\alpha}$, became stronger (see Luraghi 1996).

Patterns of case variation described in this section are summarized in Table 1:

Table 1. Patterns of case variation

\begin{tabular}{llll}
\hline & dative & genitive & accusative \\
\hline $\begin{array}{c}\text { variation connected } \\
\text { with different }\end{array}$ & location & source & direction \\
semantic roles & & \\
variation connected & - non-ablative & - non-directional \\
with profiling of & - discontinuous & - continuous landmarks \\
the same & landmarks & - extension of the \\
semantic role & - point on a & landmark \\
& & landmark & - multidirectional path \\
& & - unidirectional path & \\
\hline
\end{tabular}




\section{The Semantics of $\delta$ เó in Homeric Greek ${ }^{10)}$}

The preposition $\delta ı \alpha$ has a basic local meaning 'through'.11) It admits case variation, and can take the genitive or the accusative. As I have mentioned above, in Classical Greek, local meaning is limited to occurrences where $\delta ı \alpha$ takes the genitive, and expresses path. ${ }^{12)}$ Occurrences with the accusative, on the other hand, express cause.

In Homeric Greek, $\delta\llcorner\alpha$ with the accusative retained a spatial meaning, which is usually glossed as virtually identical with the spatial meaning of $\delta ı \alpha$ with the genitive, i.e. as 'through'. When $\delta\llcorner\alpha$ occurs with motion verbs it is said that the accusative puts more emphasis on the extension of the entity referred to by the landmark, but it is not normally questioned whether the type of motion described by $\delta \dot{\alpha}^{\alpha}$ with the accusative or genitive is the same. Still, there are occurrences where the two cases appear not to be interchangeable, as I will show below.

Part of the problem of understanding the role of the accusative with $\delta$ i $\alpha$ and its semantic effect on specific PPs arises from the failure to distinguish between its directional and non-directional meanings. This in its turn is due to two factors: in the first place, occurrences where $\delta i \alpha$ with the accusative has spatial meaning are not numerous, and within this limited number directional usages of the accusative with $\delta$ i $\alpha$ are very few. In the second place, since the preposition always indicates path, non-directional usages occur with motion verbs, in very much the same way as directional ones. This is not the case, for example, with $\mu \varepsilon \tau \dot{\alpha}$ : with $\mu \varepsilon \tau \dot{\alpha}$, directional usages of the accusative occur with motion verbs, and nondirectional ones with verbs of rest; for this reason, no confusion arises.

$\Delta เ \alpha$ is not unique in presenting directional and non-directional usages of the accusative with motion verbs. Another example is $x \alpha \tau \dot{\alpha}$, which means 'down(wards)' with the directional accusative as in (9), and 'around', 'among' with the non-directional accusative as in (10): ${ }^{13)}$

\footnotetext{
10) The description in this section is partly based on Luraghi $2003,168-75$.

11) On the etymology of $\delta\llcorner\alpha$ see Chantraine 1968 s.v. This particle is somewhat exceptional with respect to most other Greek prepositions/preverbs, because it never occurs in Homer as a free standing adverb, see Chantraine 1953, 95.

12) Further semantic roles expressed by $\delta$ เ $\alpha$ with the genitive are time, instrument and intermediary; see Schwyzer 1950, 450-4, and Luraghi 2003, 176-87.

13) On the meaning of $\varkappa \alpha \tau \alpha \dot{~ i n ~ H o m e r, ~ s e e ~ C h a n t r a i n e ~ 1953, ~ 112-5, ~ a n d ~ L u r a g h i ~ 2003, ~ 197-204 . ~}$
} 


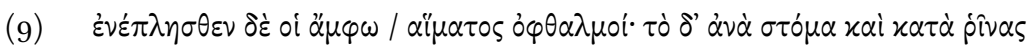
/ $\pi \rho \hat{\eta} \sigma \varepsilon \chi \alpha \nu \omega^{\prime} \nu$ (Il. 16.348-50)

Both his eyes were filled with blood: up through his mouth and down his nostrils he spurted blood as he opened his mouth

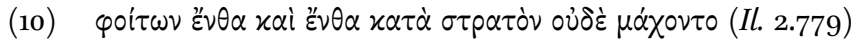

They wandered here and there throughout the camp and did not fight

In (9), the trajector moves downward along a unidirectional trajectory. This interpretation is supported by knowledge regarding the shape of the landmark pivas 'nostrils', which constrains the shape of the trajectory. In (10), on the other hand, the occurrence of the adverbs है $v \theta \alpha$ x $\alpha$ है $v \theta \alpha$ 'here and there' indicates that motion is performed randomly, rather than toward a certain direction: this is an occurrence of multidirectional trajectory, or multidirectional path.

In much the same way as with $\delta$ i $\alpha$, with $x \alpha \tau \dot{\alpha}$ occurrences of the directional accusative are outnumbered to a great extent by those of the nondirectional accusative (cf. George 2006); however, the semantic difference between them is clearer, because contextual factors favor one or the other interpretation, as shown in the examples just discussed.

\subsection{Unidirectional and Multidirectional Path / Single and}

\section{Multiple Location}

Both with the genitive and with the accusative, $\delta$ เ $\alpha$ occurs most often with motion verbs; however, some occurrences refer to stationary situations. I group the latter occurrences together with those where the difference between the genitive and the accusative with motion verbs may be captured in terms of plexity, either of the trajectory (motion verbs) or of the trajector (verbs of rest).

\subsection{1 $\Delta$ เó with the Genitive}

Before discussing the meaning of $\delta\llcorner\alpha$ with the accusative, I will briefly describe the meaning of $\delta$ i $\alpha$ with the genitive, which is much less controversial. Note that, contrary to its wider range of meanings in later prose, $\delta i \alpha$ with the genitive only has spatial usages in Homer; it is more frequent than $\delta\llcorner\dot{\alpha}$ with the accusative (97/77), especially if one only considers space 
expressions (97/64). ${ }^{14)}$ It may occur with verbs of motion or of rest. In the first type of occurrences, $\delta$ i $\alpha$ with the genitive indicates the path along which a trajector is moving; the trajectory is meant to be unidirectional. This is most clear when either the type of landmark or the type of trajector constrains the shape of the trajectory, as in (11), (12) and (13):

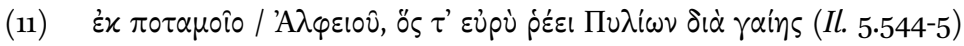

From the river Alpheus, which flows through the Pylian land

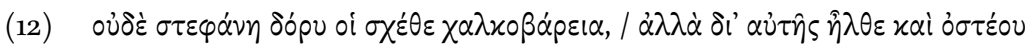
(Il. 11.96-7)

Nor was the spear stayed by his helmet, heavy with bronze, but passed through it and through the bone

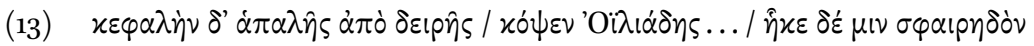

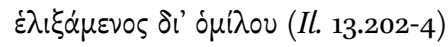

The son of Oileus cut the head from the tender neck, and with a swing he sent it rolling through the throng like a ball

In (11), the path corresponds to the course of a river, which is the trajector. Such a trajector may change its direction, but it always flows along a detectable trajectory, rather than possibly moving around in various directions. Example (12) is one of a sizable number of passages where $\delta \dot{\alpha} \alpha$ with the genitive indicates the trajectory of a weapon (usually a spear) which crosses a coverage (such as a shield or a helmet) or a body part and produces a wound (cf. Chantraine 1953, 95). Clearly, such a trajector cannot move around randomly inside the landmark, but it necessarily moves in a specific direction. Finally, in (13) the trajector is the head of the hero cut off from his neck by a stroke of the enemy: in this case, too, the trajectory can only be unidirectional, since a body which moves as a result of a stroke cannot change direction unless some external cause intervenes. ${ }^{15)}$

14) Contrary to $\delta ı \alpha$ with the genitive, $\delta ı \alpha$ with the accusative is not limited to space expressions in Homeric Greek, but can also indicate cause. Cause expressions are left out of consideration in the current discussion.

15) The same type of motion is described in Il. 11.147, in which the headless whole body of a dead hero is described as rolling through the fighting soldiers with the verb $\chi \cup \lambda i v \delta \varepsilon \sigma \theta \alpha$. 
In many other occurrences, the shape of the trajectory is not, in principle, constrained by the type of landmark or the type of trajector. Consider for example (14), in which the landmark is constituted by the warriors:

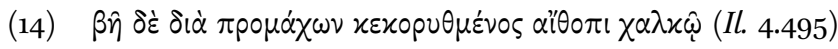

(He) strode amid the foremost warriors, harnessed in flaming bronze

This is a formulaic verse, which also occurs in six other passages in the Iliad. This landmark occurs fifteen times in the Iliad, always in the geni-

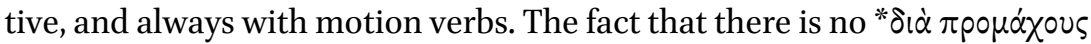
could be taken as evidence for lexical distribution of landmarks, with small connection to any semantic difference. Note however that the accusative would fit the meter equally well as the genitive:16) this latter argument supports the idea that the genitive is chosen because the accusative would also imply some semantic difference. In order to support this second view, I will now discuss some occurrences where the accusative indicates multidirectional path inside a landmark.

\subsection{2 $\Delta$ เó with the Accusative}

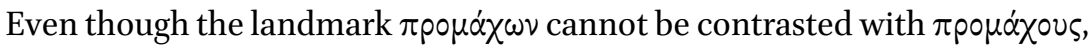
one can contrast it with another human landmark, $\sigma \varphi \varepsilon$ ćs in (15):

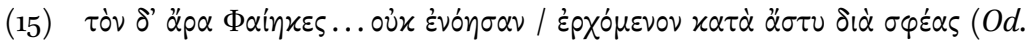
7.39-40)

But as he went around in the city among them, the Phaeacians took no heed of him

In (15), the trajector $\tau$ óv, which refers to Odysseus, does not move along a unidirectional path: rather, Odysseus is described as wandering around in the town, as indicated by the occurrence of $x \alpha \tau \dot{\alpha}$. Accordingly, he does not go straight through a group of people, but rather moves around among

16) The PP $\delta ı \dot{\alpha} \pi \rho \circ \mu \alpha \alpha \chi \omega \nu$ occurs thirteen times starting in the second foot, and twice starting in the third; the similarity of the verses where it occurs points toward the highly formulaic character of the PP. 
them: this is indicated by the occurrence of the accusative, rather than the genitive.

Another occurrence in which the accusative can be compared with the genitive is (16), where the verb $\dot{\varepsilon} \lambda i \sigma \sigma \varepsilon \sigma \theta \alpha$ l 'roll' is the same as in (13):

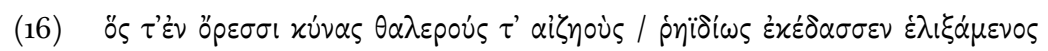

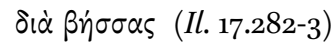

(a wild boar) that lightly scatters hounds and vigorous youths running around through the glens

In (16) the trajector does not roll along a straight trajectory, as in (13): rather, the boar runs in different directions in order to fight against the hounds and the men who chase it. The difference between the two types of motion is represented in Figure 1:

example (13) example (16)
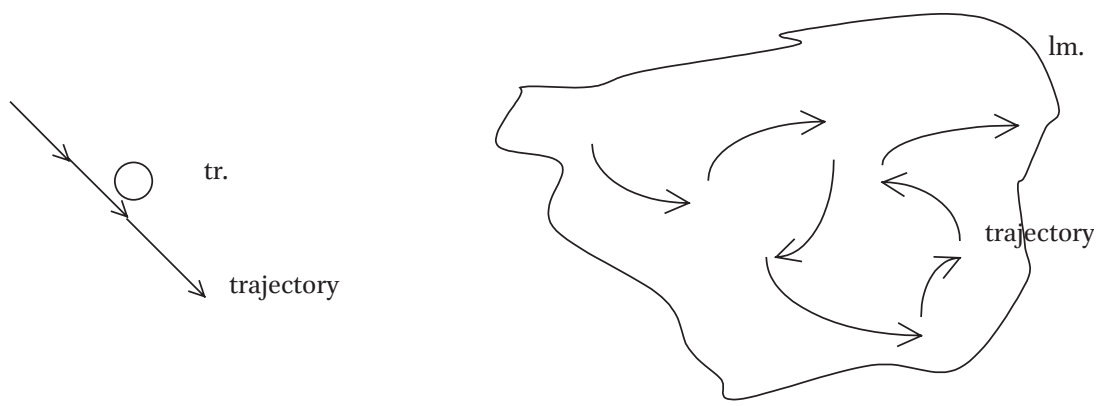

Figure 1. Unidirectional vs. multidirectional path (adapted from Luraghi 2003, 171)

Most often, $\delta\llcorner\alpha$ with the genitive and with the accusative do not occur with the same landmark, as in the examples discussed above. However, in (17) and (18) we do find the same landmark:

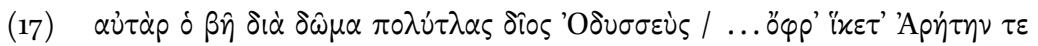

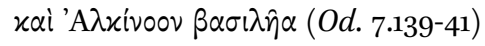


But the much-enduring goodly Odysseus went about in the hall until he came to Arete and to Alcinous the king

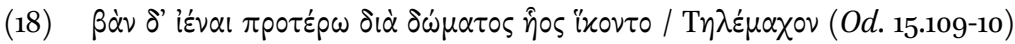

They walked through the hall, until they reached Telemachus

Ancient commentators, who no longer understood the local meaning of $\delta$ i $\alpha$ with the accusative, suggested that the accusative in (17) corresponded to their usage of the genitive, even though some noted that Homer sometimes used $\delta\llcorner\dot{\alpha}$ as equivalent of $\varkappa \alpha \tau \dot{\alpha}$ (cf. Ebeling 1885, 298) which made more sense in the framework of their own knowledge of the language.

It must be immediately said that (18) is the only occurrence of a genitive with this landmark: elsewhere, either $\delta\llcorner\dot{\alpha} \delta \hat{\omega} \mu \alpha$ or $\delta\llcorner\dot{\alpha} \delta \omega \mu \alpha \tau \alpha$ occur, depending on metrical factors. Indeed, the genitive in (18) could also be explained as being used in order to prevent hiatus, as does Ebeling. However, in view of the meaning of $\delta \dot{\alpha}^{\alpha}$ with the accusative as described above, a meaning difference might be detected between (17) and (18) as well. Let us start with $\delta \dot{\alpha} \delta \hat{\omega} \mu \alpha / \delta \omega^{\prime} \mu \alpha \tau \alpha$. This type of PP occurs in the Odyssey nine times (twice in identical occurrences), with fairly different verbs, and the passages where it occurs do not seem to be highly formulaic. An interesting example, which is also discussed in Ebeling 1885, 298-9, is (19):

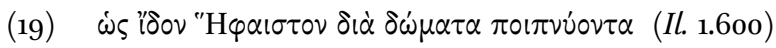

As they saw Hephaestus puffing through the palace

Ebeling correctly remarks that the motion can only be performed "hic illic in aedibus, non recte": and indeed, if someone is walking around in a building preparing dinner, we expect that s/he does not move on a straight line, but rather walks around in different directions. Note that Ebeling indicates that the trajector moves along a multidirectional path in the case of example (16) as well: "huc illuc per valles", giving the same interpretation as the one illustrated above in Figure 1. His conclusion, though, is different, since he fails to recognize the structure of the trajectory as the basic feature which triggers the occurrence of either case. He writes: "notat enim acc[usativus] id quod movetur secundum spatium aliquod atque intra,..., quando non per totum, sed per partem tantum motus fit". Note that the description of the meaning of the genitive with $\delta$ i $\alpha$ is "per, de iis 
quae totum transeunt et in alteram partem exeunt". In other words, according to Ebeling case variation depends on whether the landmark is crossed from side to side, or whether the trajector remains inside it. Now, while it is indeed true that trajectors usually move inside accusative landmarks of $\delta \dot{\alpha}$, there is not enough evidence for assuming that trajectories which cross genitive landmarks always end outside them. For example, let us consider (20):

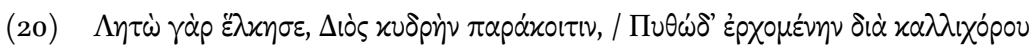

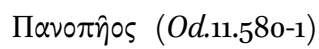

For he had performed violence onto Leto, the glorious wife of Zeus, as she went toward Pytho through Panopeus with its lovely lawns

The passage is about the giant Tityus. According to Greek mythology, Tityus attempted to rape Leto while at Panopeus, not after she crossed it. ${ }^{17)}$ Similarly, in (21) it is not said that Odysseus leaves the ship after having gone across it, but rather that he moves along a trajectory which is completely included inside the ship:

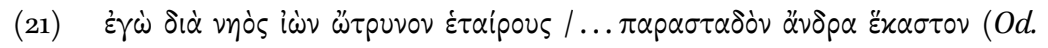
12.206-7)

I went through the ship and cheered my men coming up to each one in turn

In (21), one can observe that the trajectory is described as systematically touching all relevant points, as is made clear by the following context, in which Odysseus refers to his comrades: as Ebeling remarks, motion takes place "per totam navim, singulos adiens". Thus, even if the trajector might be thought of as changing direction while moving through the ship, the genitive profiles the fact that it touches all relevant points: this makes the

17) The anonymous referee points out that "Leto's (intended) trajectory does indeed terminate outside the landmark Panopeus". However, while I agree on the referee's remark that "[t] he fact that she does not cross Panopeus completely is not expressed by $\delta \dot{\alpha} \alpha+$ gen. but rather by the present stem", it still remains that the landmark is not completely crossed: so $\delta \iota^{\alpha}$ with the genitive is not limited to occurrences in which it indicates complete crossing of a landmark. 
trajectory detectable, while it would not be so if Odysseus had given an indication that he had addressed randomly just some of his men.

Returning now to (17) and (18), where both trajectories are said to stop when the desired referent is reached, it appears that the two occurrences may be distinguished even without resorting to metrical factors by extending the analysis of (19) to (17). Following this analysis, one must interpret (17) as meaning 'he went around in the palace, until he reached...', while the meaning of $(18)$ is 'they went straight through the palace, until they reached...' (see below, section 5 for further discussion of metrical factors and case variation).

Another landmark which occurs both in the genitive and in the accusative is $\pi$ ó $\lambda$ เs. Examples are (22) and (23):

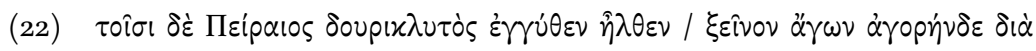
$\pi \tau \dot{\lambda} \lambda$ lv (Od. 17.71-2)

Then Peiraeus, the famous spearman, drew near, leading the stranger through the city to the place of assembly

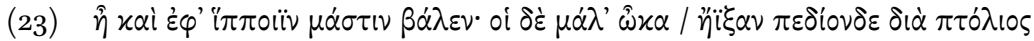
$\mu \varepsilon \mu \alpha \omega \hat{\tau \varepsilon \varsigma ~(O d . ~ 15.182-3) ~}$

He spoke, and touched the two horses with the lash, and they sped swiftly toward the plain, coursing eagerly through the city

In the two occurrences above, it is easier to show that the type of trajectory involved is not the same. In (23) the horses are depicted as running through the town as a result of having been lashed. Typically, one spurs one's horses because one wants to guide them in a straight direction, and not in order to have them run around randomly. On the other hand, (22) refers to Peiraeus walking in town with Odysseus, who is disguised as a beggar: this type of motion is not purposeful and directional, rather, a beggar goes around begging at different places (and this is also what one understands if one reads the previous context). ${ }^{18)}$

18) Even though it can be remarked that Peiraeus was leading Odysseus to the place purposefully. 
All occurrences of landmarks in the accusative discussed thus far contain uniplex trajectors moving along multidirectional paths. In (24) a multiplex trajector is described as moving in different directions:

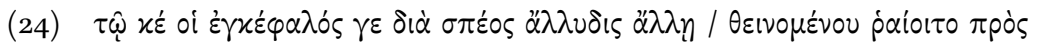

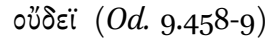

Should his brains be dashed on the ground here and there throughout the cave

In (24) the smashed brain of the victim is described as dashed around in small bits: rather than one, multidirectional path, here we find several trajectories, each of which has a different direction. With genitive landmarks, trajectors are most often uniplex; even in case of multiplex trajectors, however, the trajectory remains one and unidirectional, as in the case of (23), where the two horses are described as rushing together in the same direction. The difference is represented in Figure 2:

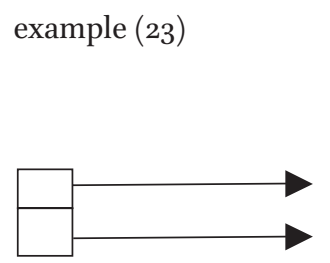

$$
\text { example (24) }
$$

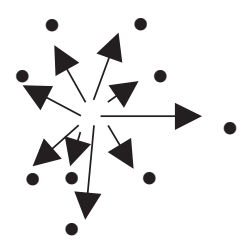

Figure 2. Single vs multiple trajectories

Thus, one can conclude that plexity of the trajector has consequences for the path only with landmarks in the accusative, which occur with uniplex trajectors and multidirectional path vs multiplex trajectors and multiple paths; on the other hand, in the case of genitive landmarks both uniplex and multiplex trajectors move along a single unidirectional path.

\subsubsection{Verbs of Rest}

In a number of occurrences, $\delta i \alpha$ with the accusative occurs in stationary situations and indicates location. In such passages, the preposition 
indicates that a multiplex trajector lies scattered on the surface occupied by the landmark, or inside the landmark. Thus, only plural count nouns or singular mass nouns (i.e. nouns indicating multiplex entities) occur in such situations, as shown for example in (25) and (26):

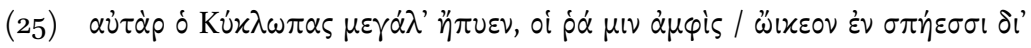

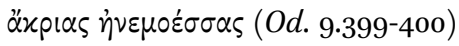

Then he called aloud to the Cyclopes, who dwelt round about him in caves among the windy heights

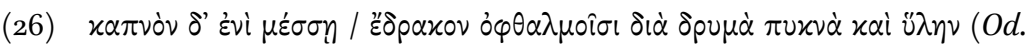
10.196-7)

In the midst (of the island) my eyes saw smoke through the thick bush and the wood

In (25) the trajector is a plural count noun. This passage can be compared with (27) where the genitive occurs:

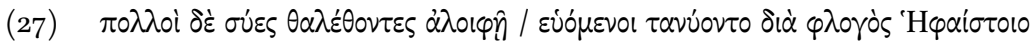
(Il. 9.467-8)

Many swine, rich with fat, were stretched to singe over the flame of Hephaestus

Here, no motion is indicated, but $\delta i \alpha$ occurs with a straight trajector (i.e. swine on a spit), and describes its position as the result of a previous movement along a uni-directional path. In much the same way as with verbs of motion (see section 4.1.2), number, which reflects plexity, is only relevant in the case of landmarks in the accusative, as in (25), where the Cyclopes are said to live in various locations, inside the area delimited by the mountains. The same position could not be occupied simultaneously by a uniplex trajector. On the other hand, in (27), where we find a landmark in the genitive, one might as well have a uniplex trajector: what is relevant is that the trajector(s) is/are envisaged as stretched in the area occupied by the landmark, so the meaning of the preposition is equivalent to the meaning found with motion verbs. Indeed, a uniplex trajector occurs with the same verb: 


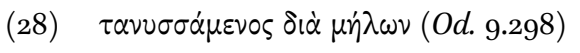

stretched among the sheep

The difference between (27) or (28) and (25) is represented in Figure 3:
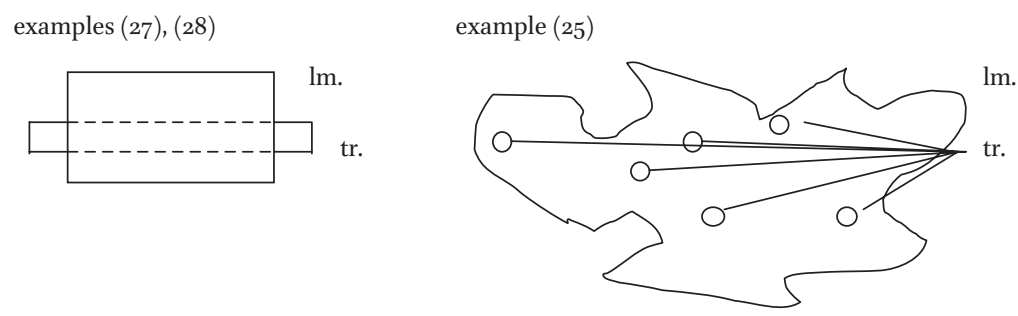

Figure 3. Unique vs multiplex location

In (26) the trajector (smoke) is a mass noun, i.e. a multiplex continuous entity. Its position inside the landmark is not clearly detectable: rather, the trajector is a loose mass located inside the area of the landmark, an area which is itself constituted by ill-detachable parts. The internal structure of multiplex landmarks is a crucial factor in determining the occurrence of the accusative or the genitive with many prepositions in Homer. The genitive, which has a partitive meaning, profiles multiplex landmarks as discontinuous, consisting of detachable parts. Let us compare (26) with (29):

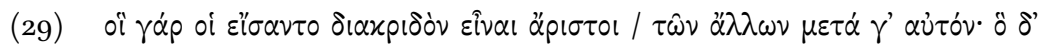

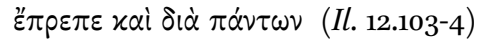

For these seemed to him to be the bravest beyond all others after his own self, for he was pre-eminent even amid all

While the mass noun in (26) refers to an entity whose localization escapes precise individuation, the singular count noun in (29) refers to an entity which can easily be located with respect to a background. The difference is shown in Figure 4. 


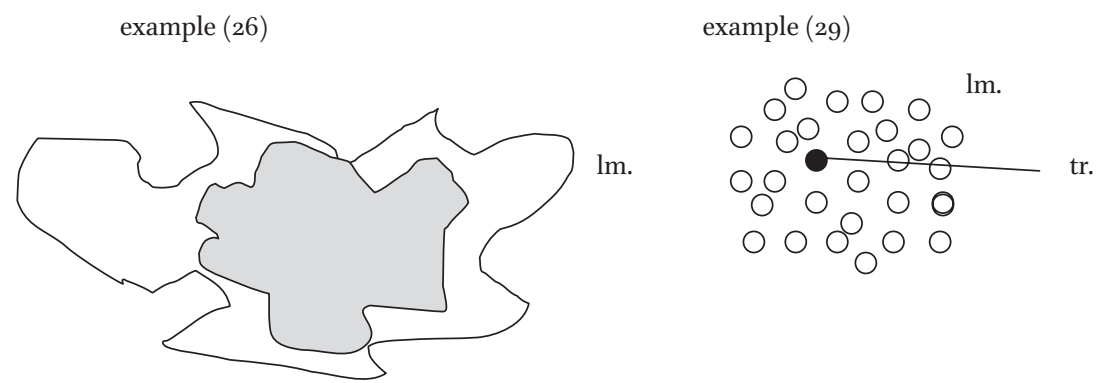

Figure 4. Unspecific vs specific location

\subsection{Directional Accusative}

One of the reasons for the confusion about the meaning of $\delta i \alpha$ with the accusative lies in the fact that no distinction is normally made between directional and non-directional meaning of the accusative with this preposition, even though this semantic difference is usually recognized for the accusative with other prepositions. Chantraine (1953, 97), for example, writes "l'emploi de l'accusatif, au lieu du génitif, s'explique par le fait que l'extension y est envisagée", and lists the examples without any further discussion of what this really means. Similarly, Horrocks (1984) maintains that occurrences with landmarks in the accusative such as those in examples (15), (19) and (22) indicate "simple directional path" (p. 254); he then mentions the fact that "[t]here are also spatial uses involving a partitive genitive" (p. 255) and explains the difference as follows: "while the accusative specifies $x$ 'as a whole' as the area traversed..., the genitive limits the area traversed to the 'interior part' of $x$ ". As we will see, the directional accusative does indeed indicate that an area is crossed over completely; however, this is certainly not true of the much more numerous occurrences of multidirectional paths that we have seen thus far. Note further that failure to distinguish directional and non-directional uses of the accusative leads Horrocks to a conclusion opposite to that of Ebeling, already quoted above, regarding the extent of the part of the landmark which is actually traversed.

Indeed, contrary to the non-directional accusative, the directional accusative indicates that an area is crossed over completely, as Horrocks writes in reference to example (30): 


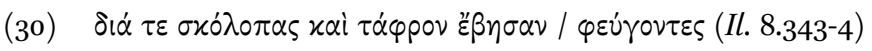

They went across the poles and the ditch in flight

In the above examples, the landmark is described as crossed over, left behind in motion, and the preposition does not profile the part of the trajectory inside the landmark's area, but rather the part that surpasses the landmark. In this case, $\delta ı \alpha$ can be rendered in English as 'across'. Comparison of the accusative with the genitive, again, is enlightening:

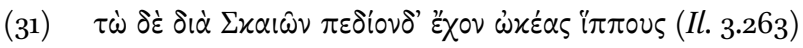

The two drove the swift horses through the Scaean gates to the plain

What is relevant in $\left(3^{0}\right)$ is that the landmark is left behind: accordingly, the accusative occurs, which, as already remarked, profiles the part of the trajectory that continues after the landmark is crossed. ${ }^{19)}$ The genitive, on the other hand, profiles the whole trajectory, as shown in Figure 5:

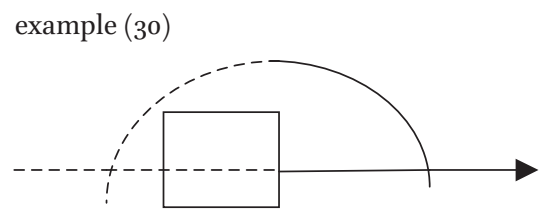

$$
\text { example (31) }
$$

Figure 5. across vs through

Two other occurrences of $\delta i \alpha$ with the directional accusative are either not discussed in handbooks, or they are taken as if the PP indicated multidirectional path, even though translations show that this cannot be the case. Consider the following examples:

19) The fact that the trajectory does not remain inside the landmark in such occurrences of $\delta \dot{\alpha} \alpha$ with the accusative obviously creates problems for Ebeling's interpretation of the meaning of landmarks in the accusative with this preposition, which he sees as necessarily connected with trajectories enclosed in the interior of landmarks conceived as closed areas. Thus he attempts various explanations, partly from ancient scholiasts: regarding (30) he mentions a gloss which interprets $\delta i \dot{\alpha} \tau \alpha \dot{\alpha} \varphi \rho \circ v$ as $\dot{\pi} \pi \dot{i} \tau \dot{\alpha} \varphi \rho \circ v$ i.e. 'up to the ditch' (without crossing it), with no regard for the overall meaning of the text, which clearly implies crossing. 


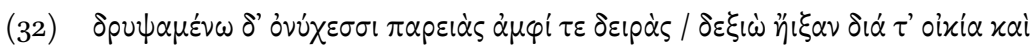

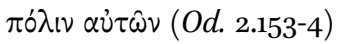

Then they tore with their talons one another's cheeks and necks on either side, and darted away to the right across the houses and the city of the men

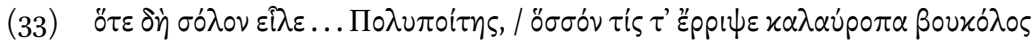

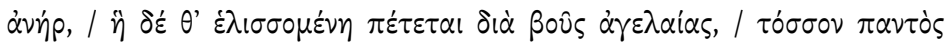

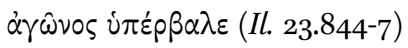

When Polypoetes grasped the mass, far as a herdsman flings his crook, and it flies whirling over the cattle, even so far cast he it beyond all the gathering

In reference to (33), Ebeling $(1885,299)$ offers the translation 'inter boves', and includes this occurrence in the same group as (16): however, the context makes it clear that this interpretation is impossible. In the first place, an object thrown by a person cannot move along a multidirectional path, but rather it moves along a unidirectional trajectory; in the second place, what is highlighted here is the fact that Polypoetes cast his disc (or such) beyond the gathering, as indicated by the verb $i \pi \varepsilon \rho \beta \alpha \lambda \lambda \lambda \omega$. Thus, the $\delta$ i $\alpha$ phrase can only mean that the crook of the herdsman goes beyond the cattle. Similarly, in (32), which is part of the description of an omen, two eagles are seen by Telemachus flying beyond the houses and the town, and certainly not among them.

Because $\pi o^{\prime} \lambda \iota \varsigma$ is a landmark which also occurs with the non-directional accusative, Ebeling mentions this occurrence without discussing it, together with the occurrence here referred to as example (22). Two other passages involve a directional usage of the accusative and a non-directional one with the same landmark, $\sigma \tau o ́ \mu \alpha$. Compare:

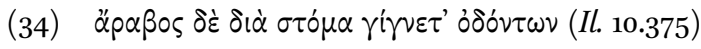

The teeth clattered in his mouth (lit.: a noise made by his teeth arose inside his mouth)

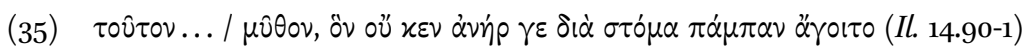
This word, that no man should in any wise suffer to pass through his mouth at all 
In these occurrences we find the same landmark, but different trajectors. In (34), ג $\alpha \alpha \beta$ $\alpha$ must be regarded as a mass noun with reference to plexity;

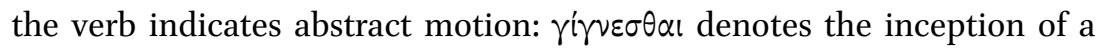
state of affairs; the noise produced by the teeth clattering spreads out inside the mouth as a mass in many directions, rather than on a straight trajectory. In (35), on the other hand, $\mu \hat{v} \theta 0$ s refers to an utterance, a unit of discourse (Odysseus reproaches Agamemnon, who had mentioned the possibility that the Greeks should flee from Troy rather than continue the war), which contains a thought that a man should not dare utter, even having conceived it. The PP $\delta \dot{\alpha} \sigma \tau \tau^{\prime} \mu \alpha$ vividly describes this state of affairs: the concept contained in the utterance should not pass through the mouth.

Another occurrence of $\delta \dot{\alpha} \alpha$ with the accusative indicating direction has proved especially puzzling for commentators, because it refers to a state of affairs typically referred to by $\delta \dot{\alpha}$ with the genitive:

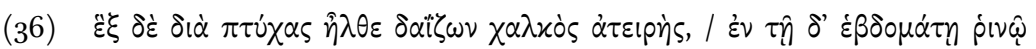

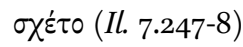

Through six folds shore the stubborn bronze, but in the seventh hide it stayed

This is the passage that both Chantraine and Horrocks mention in order to substantiate their claim that the accusative puts an emphasis on the extension of the object traversed, while the genitive does not. It can be contrasted with (37), where a landmark in the genitive occurs:

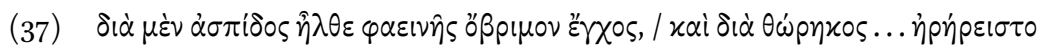
(Il. $3 \cdot 357-8)$

Through the bright shield went the mighty spear, and through the corselet did it force

Indeed the two passages are quite similar, and one could even invoke metrical factors as Ebeling seems to suggest again. However, the difference in profiling can account for case variation in the two passages: what is relevant in (36) is not that the spear went through some layers of hide, but rather that it did not go through the last one. Indeed, this is the only 
occurrence in which such a state of affairs is referred to; in all the other numerous occurrences in which the trajector is a weapon we find landmarks in the genitive, and the situation described is always one in which the weapon crosses a landmark and either produces the intended result of wounding somebody or continues its trajectory having missed its target, ${ }^{20)}$ rather than hit into another barrier which remains uncrossed. This is the case also in (37), where the spear is said to have gone through the shield and through the corselet: the whole trajectory is relevant here, and is accordingly profiled. Conversely, in (36) only the part of the trajectory which continues across the landmark is profiled, because this indicates that what is really relevant is the fact, expressed immediately thereafter, that this trajectory was stopped by another landmark.

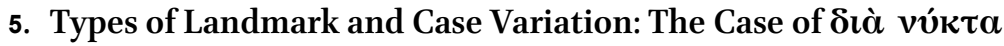

As we have seen in the above sections, the meaningfulness of case variation with $\delta$ i $\alpha$ can only partly be investigated by comparing occurrences with the same landmark: most often, landmark occurrences are limited to either case. Note further that even in the limited number of passages in which both cases occur with the same landmark metrical factors can virtually always be invoked to explain the putative 'irregularity', as I have mentioned regarding (18) and (36). Indeed, in both occurrences we find (types of) landmarks that occur several other times, but always in the other case: (18) is the only occurrence of $\delta \omega \mu \alpha \tau o \varsigma$ as landmark in the genitive (against nine in the accusative), and (36) is one of two occurrences of a landmark in the accusative in a passage in which the trajector is a weapon (against 25 occurrences with landmarks in the genitive). The other occurrence of a landmark in the genitive is in a formulaic expression, which I will discuss below (example (41)).

It may be noted that the landmark $\pi \tau$ tó $\lambda$ ıs occurs once in the genitive, once in the non-directional accusative, and once in the directional accusative, and that the different contexts in which these occurrences are

20) The latter is the case in the passage from which example (37) is taken. The following verses indicate that the spear continued and describe the further trajectory: 'and straight on beside his flank the spear shore through his tunic; but he bent aside and escaped black fate' (Il. 3·359-6o). 
found fit very well the difference in meaning of the PPs involved. However, it must be mentioned that the genitive would not fit the meter in the two passages in which the accusative occurs; in addition, one may also note that examples (20) and (21), in which a trajectory is contained in the interior of a landmark in the genitive, would not allow an accusative. Obviously, following such an extremistic approach, one might re-write the whole Homeric text; still, since some scholars seem to think that much variation in Homeric Greek is to be explained through meter, I will discuss this possibility further.

In the first place, I will focus on two PPs that always contain landmarks in the accusative, and occur in highly formulaic passages. They are $\delta i \dot{\alpha}$

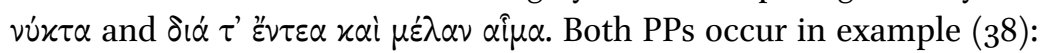

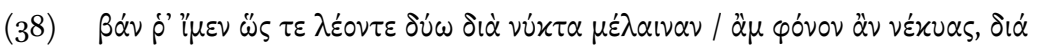

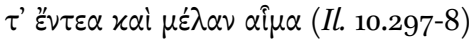

They went their way like two lions in the black night, amid the slaughter, amid the corpses, among the arms and the black blood

The PP $\delta \dot{\alpha} v \dot{u} x \tau \alpha$ is frequent: it occurs twenty times in the Homeric poems out of 67 spatial expressions with $\delta i \alpha$ and the accusative. The fact that no other landmark is so frequent with $\delta i \dot{\alpha}$ merits a separate treatment. Ebeling $(1885,299)$ and Chantraine $(1953,96)$ set up a temporal meaning of $\delta 1 \alpha$ in order to account for such occurrences; however, there appears to be no need for this: the night here is conceived as a container in which the warriors move (cf. Palmer 1962, 142 and Luraghi 2003, 173). ${ }^{21)}$ Close inspection of the occurrences indicates that this explanation also applies

21) Horrocks $(1981,255)$ leaves both possibilities open without going through all examples. Temporal meaning of $\delta \dot{\alpha} v \dot{v} x \tau \alpha$ is also assumed in the recent book by Pietro Bortone, who considers this an example of "[i]ndiscriminate use of cases in PPs", since, in his opinion, $\delta i \alpha$ could indicate duration in time both with the accusative and with the genitive. As examples, he gives (out of context) the passage quoted here as (39) and a passage from Herodotus, in which $\delta \dot{\alpha} \alpha$ with the genitive does indeed express time (Bortone 2010, 159). Apart from considerations regarding the real meaning of $\delta \dot{\alpha} \alpha \dot{v} x \tau \alpha$, we should bear in mind that neither does $\delta i \dot{\alpha}$ with the genitive express time in Homeric Greek, nor is the PP $\delta i \dot{\alpha}$

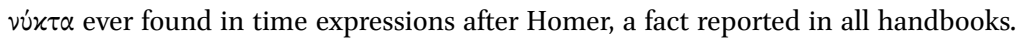


to passages which do not contain motion verbs. Let us consider the following examples:

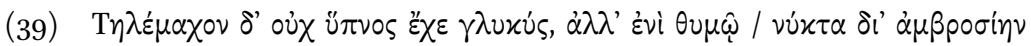
$\mu \varepsilon \lambda \varepsilon \delta \dot{\eta} \mu \alpha \tau \alpha \pi \alpha \tau \rho \dot{\varsigma} \varsigma$ है $\gamma \varepsilon ı \varepsilon \varepsilon$ (Od. 15.8-9)

Sweet sleep did not hold Telemachus, but in the immortal night anxious thoughts for his father kept him wakeful

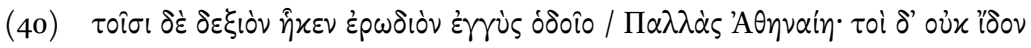

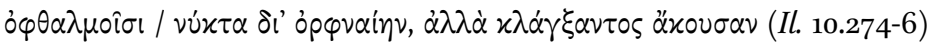

Athena sent them a heron to the right of their route: they could not see it in the dark night, but heard it screaming

If (39) is considered out of context, the translation 'throughout the night' might seem appropriate. However, the preceding context indicates that duration in time is not relevant here. The preceding verses describe a visit of Pallas to Telemachus: 'Pallas Athena went to spacious Lacedaemon to remind the glorious son of great-hearted Odysseus of his return, and to hasten his coming. She found Telemachus and the noble son of Nestor lying in the fore-hall of the palace of glorious Menelaus. Now Nestor's son was overcome with soft sleep, but sweet sleep did not hold Telemachus, but in the immortal night anxious thoughts for his father kept him wakeful.' What is relevant here is not that Telemachus has been kept awake during the whole night, but rather that he was awake at the moment when Pallas reached him. Similarly to $(38)$ the night is conceived as a container, and the accusative occurs to indicate a non-exact location. That this is actually the case becomes even more clear in example (40), in which it is said that the dark night prevents the men from seeing the heron sent by the goddess, even though they could still hear its voice. Clearly here there is an opposition between types of perception: while sight is impaired by darkness, hearing is not; any attempt to relate $\delta \dot{\alpha} \alpha$ to duration in time would overlook this fact. Note further that, contrary to other cases where the accusative occurs in location expressions, trajectors in (39) and (40) are uniplex. I will return to this important difference below. ${ }^{22)}$

22) Verbs of perception are often considered as metaphorically corresponding to motion verbs in Greek, and there is clear evidence in later Greek theories of perception for such interpretation (see Luraghi 1989). In Homer, there is also evidence for the eyes to be 
In passages in which the PP $\delta i \dot{\alpha} \nu \cup ์ x \tau \alpha$ occurs with motion verbs, it is often juxtaposed to other prepositional phrases as in (38). The second occurrence clearly describes a type of motion similar to the motion denoted by $\alpha \dot{\alpha} \alpha$, which also indicates motion along a multidirectional path

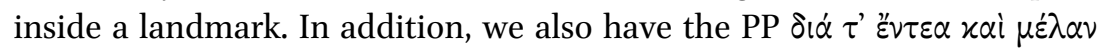
$\alpha \hat{i} \mu \alpha$, which occurs three times in the Iliad and is highly formulaic (see the discussion of example (41) below). The landmarks indicated in this passage, the night, the corpses, and the weapons and blood scattered on the battlefield, do not allow for an observer to trace the precise trajectory along which the trajector is moving. In this (and similar) case(s) it is not the nature of the type of motion itself which causes the trajectory not to be detectable and triggers the interpretation of multidirectional path: the two warriors in (38) may move along a unidirectional path, but they are depicted as doing so inside two landmarks that disguise their motion. Similarly, as I have remarked above, trajectors in (39) and (40) are uniplex. What makes the trajector's location hard to detect in these passages is not the fact that the trajector is scattered over an area as in (25) or that it is a mass noun as in (26), but the nature of the landmark, in much the same way as in (38).

Thus, the actual structure of the path becomes irrelevant: this amounts to a sort of neutralization. This is not to say that landmarks in the genitive and the accusative cannot be used contrastively in Homeric Greek, as indeed they are in most occurrences; rather, since certain landmarks favor either conceptualization of the path, the case, which also indicates the structure of the path, partly becomes redundant. This development, which is not limited to $\delta \dot{\alpha}$, but also involves case variation with other prepositions, eventually led to the loss of the opposition total/partitive (accusative/genitive), which is no longer active in Classical Greek. In addition, there can also be cases, though marginally, where it is not so relevant to indicate whether a trajectory is unidirectional or not: in this sense, one might say that the genitive in (18) is motivated by meter. This is not to say that the meaning of $\delta \dot{\alpha} \delta \dot{\omega} \mu \alpha \tau \alpha$ and $\delta i \dot{\alpha} \delta \omega \mu \alpha \tau o \varsigma$ was the same, but simply that the structure of the path was not especially relevant here.

conceived as containers, rather than channels, which could imply a stationary concept of perception (see Luraghi 2004). A discussion of this interesting issue is beyond the scope of this paper; in any case, in the light of the discussion below, it does not matter much in this context whether one takes the verb 'see' as implying metaphorical motion or not. 
As a last example, I would like to discuss (41), where indeed the formu-

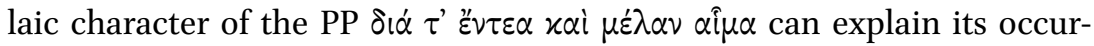
rence in a passage in which the shape of the trajectory as possibly profiled by $\delta i \alpha$ with the accusative does not fit the context.

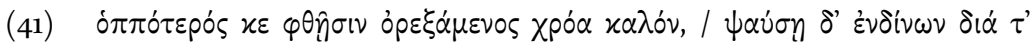

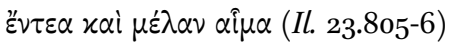

Which of the two shall first reach the other's fair flesh, and touch the inward parts through armor and dark blood

In (41) the multiple path reading cannot apply: a weapon strikes moving along a clearly detectable trajectory, and as such is normally described in the Homeric poems. Nor could one hold this for an occurrence of directional accusative: indeed, while a weapon may be conceived as going beyond an armor (as it is in (36)), this interpretation could not apply to the blood. Rather, the PP in this passage seems to contain a "standard formular enumeration" in the sense of Bakker $(1988,189)$, "whose integration in the context is less than perfect" because, as in the case of other similar enumerations, one of the items does not fit the context: while the

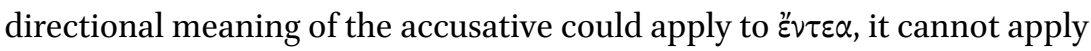
to $\alpha i \mu \alpha$, but $\varepsilon^{\prime} v \tau \varepsilon \alpha$ was often connected with the NP $\mu \varepsilon \dot{\lambda} \alpha \nu \alpha i \mu \alpha$ in this formula. Frequency of association prompts the usage of the formula here.

\section{Summary and Conclusion}

In this paper I have described the use of the accusative with $\delta \dot{\alpha} \alpha$ in spatial expressions, trying to show that there are semantic reasons for the occurrence of this case, rather than the more frequent genitive, which are connected with the type of trajectors and landmarks involved, as well as with the shape of the trajectory. Based on the passages in which either case occurs, the distribution can be explained as follows.

a. Landmarks in the genitive:

- a uniplex trajector moves along a unidirectional trajectory through the interior of a landmark (the trajectory may or may not continue outside the landmark); 
- a multiplex trajector moves in the same direction along parallel trajectories through the interior of a landmark (the trajectory may or may not continue outside the landmark);

- a uniplex trajector is located at a single position inside a landmark.

b. Landmarks in the accusative:

$b_{i}$ Non-directional usages of the accusative:

- a uniplex trajector moves along a multidirectional trajectory;

- a multiplex trajector moves along various trajectories in different directions;

- a multiplex trajector is randomly located at various points in the landmark.

$b_{\mathrm{ii}}$ Directional usages of the accusative:

- a landmark is crossed over by a trajector (usually uniplex, or multiplex but moving along the same trajectory); the trajectory continues after the landmark has been crossed over.

In addition, landmarks in the genitive always allow for detectability of trajectories or locations, while landmarks in the accusative in nondirectional usages do not. As a consequence, uniplex trajectors may also occur in stationary situations, in which specific landmarks have the effect to prevent them to be detected, as in the case of $\delta \dot{\alpha} v \dot{\alpha} x \tau \alpha$.

While non-directional usages of the accusative are more numerous, directional ones are likely to be older: the contrast between the non-directional accusative and the genitive is specific of Homeric Greek, and rests on the opposition total/partitive. The directional meaning of the accusative with motion verbs, on the other hand, is inherited from Proto-IndoEuropean. The variety of meanings conveyed by cases with prepositions were also partly conveyed by cases alone in Homeric Greek, in which PPs were yet at an early stage of grammaticalization. As a result, the same preposition could indicate the same semantic role with different cases. Later, as PPs became fully grammaticalized, this overlap became increasingly limited, also on account of a reduced impact of the opposition total/ partitive within PPs.

\section{References}

Bakker, E. 1988. Linguistics and Formulas in Homer (Amsterdam/Philadelphia) Bortone, P. 2010. Greek Prepositions. From Antiquity to the Present (Oxford) 
Chantraine, P. 1953. Grammaire homérique, t. 2: Syntaxe (Paris) 1968. Dictionnaire étymologique de la langue grecque. Histoire des mots, t. 1 (Paris)

Ebeling, H. 1885. Lexicon Homericum (Leipzig; repr. 1987, Hildesheim)

George, C. 2006. The Spatial Use of $\alpha \dot{\alpha} \alpha$ and $x \alpha \tau \dot{\alpha}$ with the Accusative in Homer, Glotta 82, 70-95

Haug, D. 2009. Does Homeric Greek Have Prepositions? Or Local Adverbs? (And What's the Difference Anyway?), in: Bubenik, V., Hewson, J., Rose, S. (eds.) Grammatical Change in Indo-European Languages (Amsterdam/Philadelphia), 103-22

Horrocks, G.C. 1981. Space and Time in Homer. Prepositional and Adverbial Particles in the Greek Epic (New York)

Langacker, R.W. 1987. Foundations of Cognitive Grammar, vol. 1: Theoretical Prerequisites (Stanford)

Luraghi, S. 1988. The Opposition Total/Partitive and the Use of Cases with Prepositions in Ancient Greek, in: Rijksbaron A. et al. (eds.) In the Footsteps of Raphael Kühner (Amsterdam), 177-92

1989. Cause and Instrument Expressions in Classical Greek, Mnemosyne 43, 294308

- 1996. Studi su casi e preposizioni nel greco antico (Milano)

2003. On the Meaning of Prepositions and Cases: The Expression of Semantic Roles in Ancient Greek (Amsterdam)

— 2004. The Container Schema in Homeric Greek, in: Soares de Silva, A., Torres, A., Gonçalves, M. (eds.) Linguagem, cultura e cognição: estudios de linguística cognitiva (Braga), 25-41

2005. The History of the Greek Preposition $\mu \varepsilon \tau \dot{\alpha}$ : From Polysemy to the Creation of Homonyms, Glotta 81, 130-59

2009. The Evolution of Local Cases and Their Grammatical Equivalent in Greek and Latin, in: Barðdal, J., Celliah, S. (eds.) The Role of Semantics and Pragmatics in the Development of Case (Amsterdam/Philadelphia), 283-305

Palmer, L. 1962. The Greek Language (London)

Schwyzer, E. 1950. Griechische Grammatik, Bd. 2: Syntax (München)

Talmy, L. 1988. The Relation of Grammar to Cognition, in: Rudzka-Ostyn, B. (ed.) Topics in Cognitive Linguistics (Amsterdam/Philadelphia), 165-205

Taylor, J.R. 1991. Prepositions: Patterns of Polysemisation and Strategies of Disambiguation, in: Zelinsky-Wibbelt, C. (ed.) The Semantics of Prepositions (Berlin/New York), 151-75 